\title{
Renal Cell Carcinoma Metastatic to the Choroid Mimicking Intraventricular Meningioma
}

\author{
Alfredo Quinones-Hinojosa, Edward F. Chang, Saad A. Khan, \\ Michael T. Lawton, Michael W. McDermott
}

\begin{abstract}
Background: Metastatic renal cell carcinoma to the choroid plexus is a rare condition and can be easily confused with meningioma. Methods: A 61-year-old female presented with progressive neurologic deterioration and MRI findings of obstructive hydrocephalus and a homogeneously contrast enhancing $3 \mathrm{~cm}$ oval mass in the trigone of the left lateral ventricle. Results: Despite radiologic, intraoperative gross features, and frozen pathology all consistent with meningioma, the final pathology revealed metastatic renal cell carcinoma. Conclusion: Renal cell carcinoma metastatic to the choroid plexus can mimic intraventricular meningioma. We present a review of the literature and comparison of the radiological features of meningiomas and metastatic renal cell carcinoma. We also discuss the use of an under-utilized technique, the contralateral transcallosal approach, in the surgical treatment of this intraventricular lesion.
\end{abstract}

RÉSUMÉ: Carcinome rénal avec métastase à la choroïde simulant un méningiome intraventriculaire. Introduction: Le carcinome rénal avec métastase au plexus choroïde est une pathologie rare et il peut facilement être confondu avec un méningiome. Méthodes: Une femme âgée de 61 ans a consulté pour une détérioration neurologique progressive et l'IRM a montré une hydrocéphalie obstructive et une masse ovale rehaussante de façon homogène de trois $\mathrm{cm}$ dans le trigone du ventricule latéral gauche. Résultats: Malgré un aspect macroscopique et radiologique ainsi qu'un examen anatomopathologique sur spécimen congelé compatibles avec un diagnostic de méningiome, l'examen anatomopathologique final a montré qu'il s'agissait d'un carcinome rénal métastatique. Conclusions: Un carcinome rénal métastatique au plexus choroïde peut simuler un méningiome intraventriculaire. Nous présentons une revue de la littérature et comparons les caractéristiques radiologiques des méningiomes et du carcinome rénal métastatique. Nous discutons également de l'utilisation d'une technique sous-utilisée, l'approche transcalleuse contralatérale, dans le traitement chirurgical de cette lésion intraventriculaire.

Can. J. Neurol. Sci. 2004; 31: 115-120

Solitary metastases to the choroid plexus are very rare. Three large postmortem series have reported the frequency of metastases to the choroid plexus as being $0.9 \%, 2.6 \%$, and $4.6 \%$ in patients with systemic cancer. ${ }^{1-3}$ Radiographically, tumors metastatic to the choroid plexus of the trigone can mimic intraventricular meningiomas. Only six cases of renal cell carcinoma metastatic to the choroid plexus have been reported in the literature; three occurred in the trigone of the lateral ventricle. ${ }^{1,3-7}$ Of these three reports, only one mentions the neurosurgical approach taken for its resection. ${ }^{1}$

We report a case of renal cell carcinoma metastatic to the choroid plexus removed via the contralateral transcallosal approach with image guidance for complete resection of the tumor. In addition, we review the literature on renal cell carcinoma metastatic to the choroid plexus, compare the radiological features of meningiomas and renal cell carcinoma metastatic to the choroid plexus and discuss the benefits of the contralateral transcallosal approach to lesions in the dominant trigone as compared to other traditional approaches.

\section{CASE RePORT}

A 61-year-old woman, right hand dominant, presented with complaints of dizziness, several months of headache and occasional right lower extremity numbness and confusion. Her past medical history

From the Department of Neurosurgery, University of California San Francisco, San Francisco, California, USA (AQ-H, EFC, MTL, MWM); McGill University Faculty of Medicine, Montreal, Canada (SAK).

ReCEIVEd APRIL 9, 2003. ACCEPTED In FINAL FORM JunE 25, 2003.

Reprint requests to: Alfredo Quinones-Hinojosa, Department of Neurological Surgery, University of California, San Francisco, 505 Parnassus Avenue, M-779, San Francisco, CA 94143-0112 USA 


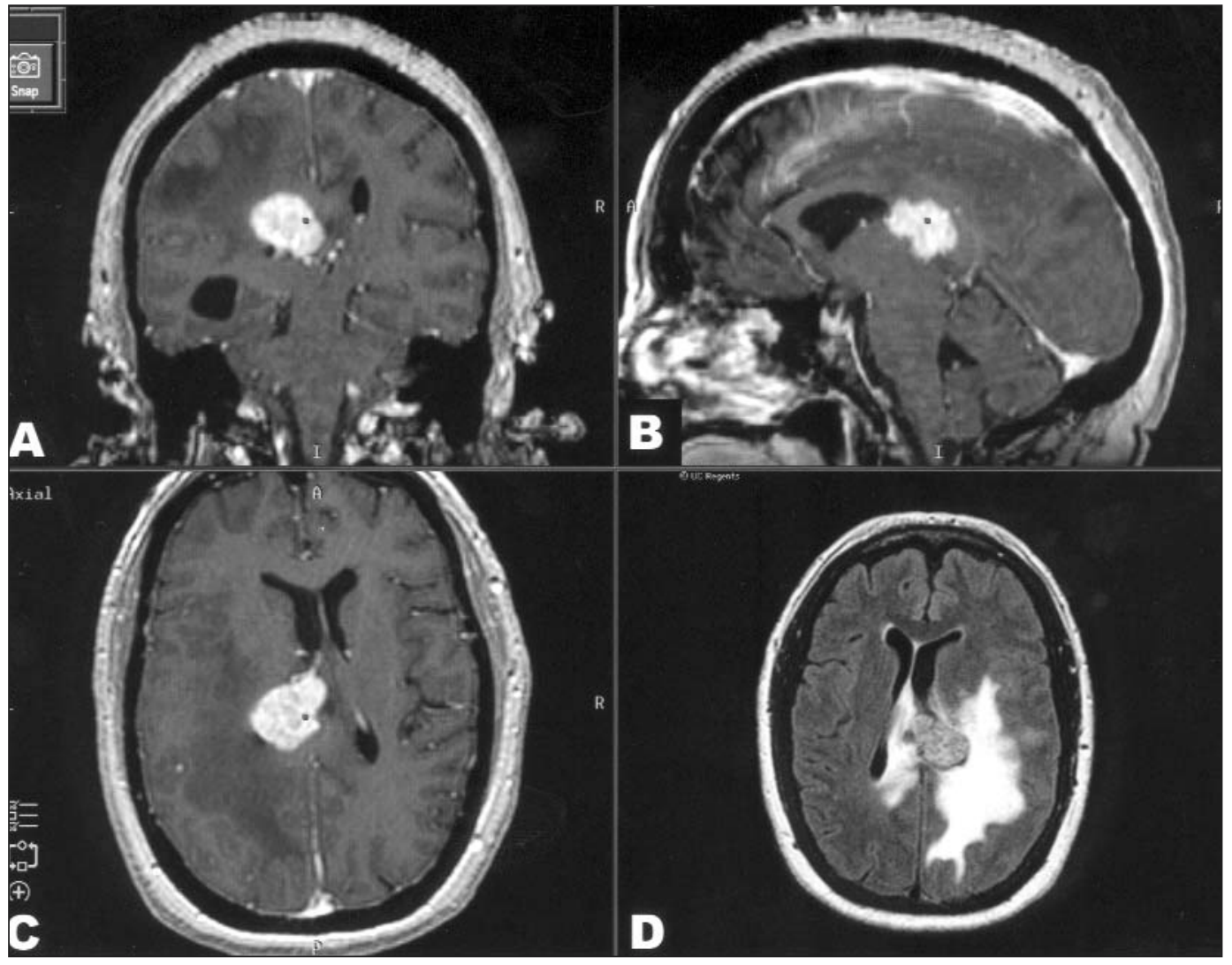

Figure 1: Preoperative MRI. (A) coronal, (B) saggital, and $(\boldsymbol{C})$ axial T1WI Stealth MRI demonstrates a $3 \times 2 \mathrm{~cm}$ mass in the posterior left lateral ventricle (in images $A \& C$ the tumor appears on the left side of the picture as it is conventional in MRI surgical navigational imaging). (D) T2WI FLAIR shows extensive T2 prolongation in the left posterior frontal and parietal lobes consistent with edema. Radiologically, this was most suspicious for an invasive, malignant-type meningioma.
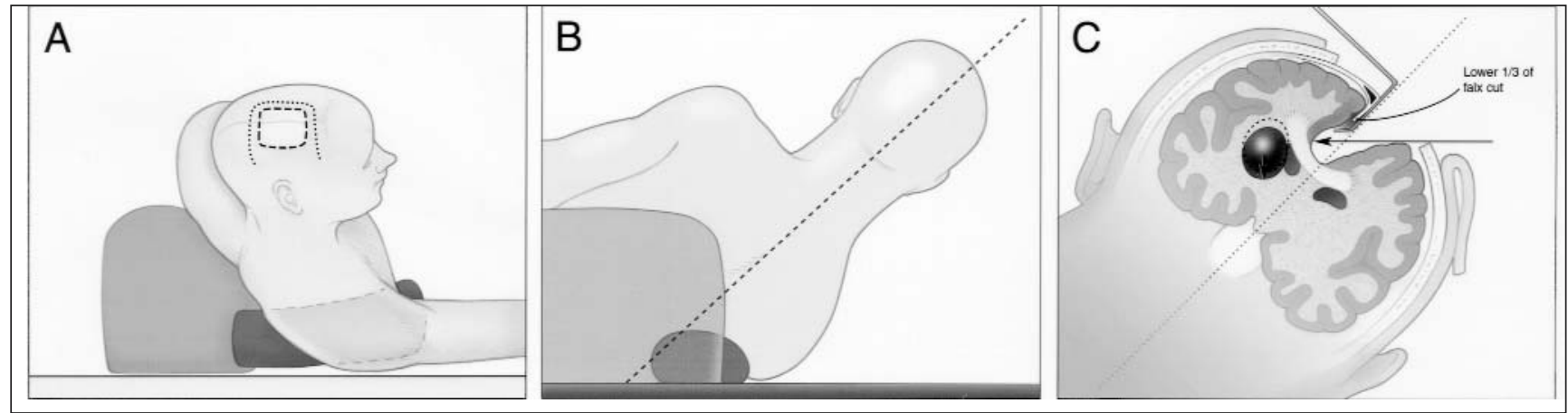

Figure 2: $(\boldsymbol{A})$ and $(\boldsymbol{B})$ patient positioned for a contralateral transcallosal approach to left intraventricular lesion, with head turned to right, the left shoulder bolstered, and the skin flap based on the right. Our surgical technique differs from that of Lawton et al. in that the skin incision, the craniotomy, and the callosotomy are done more posterior to the coronal suture. (C) Gravity retracts the contralateral hemisphere, opens the interhemispheric fissure, and pulls the lesion into the surgeon's view. (Adapted from Lawton et al, 1996 ${ }^{26}$ ).

was significant for a nephrectomy for renal cell carcinoma 10 years prior to presentation. Her neurological exam was intact but her fundi showed early papilledema. A pre-operative MRI demonstrated a homogeneously contrast enhancing $3 \mathrm{~cm}$ oval mass in the posterior body of the left lateral ventricle just above the area of the trigone with obstruction and dilatation of the temporal horn and atrium of the left lateral ventricle (Figure 1). There was considerable vasogenic edema (extensive T1 and $\mathrm{T} 2$ prolongation in the surrounding white matter). The radiological 


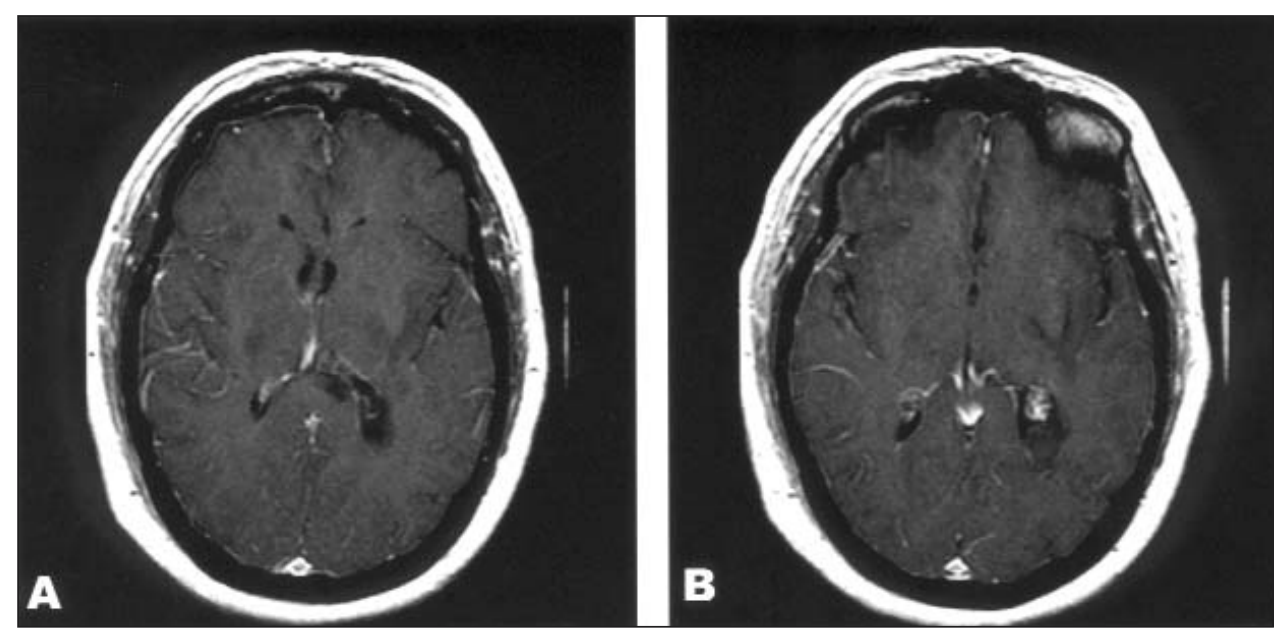

Figure 3: Postoperative MRI-T1WI with contrast $(A \& B)$ demonstrating total resection of the renal cell carcinoma.

provisional diagnosis of meningioma was made. Surgical removal was recommended for diagnosis and to relieve obstructive hydrocephalus.

The patient was taken to the operating room where she underwent a right parietal craniotomy and right (contralateral) transcallosal approach for complete microsurgical resection of the left sided intraventricular tumor with surgical navigation (Stealth System, Sofamor Danek, Memphis TN) (Figure 1). The patient was placed in a right lateral decubitus position and a u-shaped scalp incision extending across the midline to the left was made to allow an interhemispheric approach and retraction of the falx (Figure 2). Once the initial dissection of the middle third of the interhemispheric fissure was accomplished, the falx was incised from just below the superior sagittal sinus down through its inferior aspect to allow some flexibility with medial retraction for this approach. The position on the posterior aspect of the corpus callosum was confirmed with image guidance to be immediately above the anterior aspect of the tumor and the callosotomy was accomplished with bipolar and suction. This provided immediate access to the tumor, which was observed to be pink and slightly vascular, and had gross features similar to a meningioma. Dissecting just anterior to this, the body of the lateral ventricle was entered with release of cerebrospinal fluid and the tumor was observed to be attached to the choroid plexus within the posterior body of the lateral ventricle. Posteriorly, the turn of the ventricle was identified between the body and atrium of the ventricle while maintaining the plane between the ependymal surface and the tumor. A biopsy specimen was obtained and the preliminary pathological diagnosis of the frozen section was benign meningioma. The tumor dissection and debulking was continued under the operating microscope. Ultimately the posterolateral aspect of the tumor was exposed as was the atrium, glomus and a large anterior choroidal artery entering directly into the tumor. The choroid plexus was extensively coagulated as was the anterior choroidal artery in this region and the tumor was resected in its entirety. Complete hemostasis was achieved and an external ventricular catheter was placed into the atrium. Postoperatively the patient did well and MRI confirmed gross total resection of the tumor (Figure 3). Subsequent workup failed to show any other tumor sites.

The final pathological diagnosis after further examination was renal cell carcinoma metastatic to the choroid plexus (Figure 4). The tumor histology demonstrated the characteristic pattern gland tissue with nests

\section{Table 1: Literature review of renal cell carcinoma metastatic to the choroid plexus}

\begin{tabular}{|c|c|c|c|c|c|}
\hline Case & Author & Location & $\begin{array}{l}\text { Vasogenic } \\
\text { Edema }\end{array}$ & $\begin{array}{l}\text { Preoperative } \\
\text { Diagnosis }\end{array}$ & Surgical approach \\
\hline 1 & Shigemori et $\mathrm{al}^{4}$ (1987) & Body of right lateral ventricle & absent & $\mathrm{n} / \mathrm{a}$ & $\mathrm{n} / \mathrm{a}$ \\
\hline 2 & Mizuno et $\mathrm{al}^{5}(1992)$ & Body of left lateral ventricle & present & $\begin{array}{l}\text { Renal cell } \\
\text { carcinoma }\end{array}$ & $\begin{array}{l}\text { Posterior interhemispheric } \\
\text { transcallosal }\end{array}$ \\
\hline 3 & Kohno et $\mathrm{al}^{1}$ (1996) & Trigone of right lateral ventricle & present & $\mathrm{n} / \mathrm{a}$ & Transcallosal \\
\hline 4 & Matsumura et $\mathrm{al}^{6}$ (1997) & Body of right lateral ventricle & present & $\mathrm{n} / \mathrm{a}$ & $\begin{array}{c}\text { Transventricular through a } \\
\text { small corticotomy }\end{array}$ \\
\hline 5 & Raila et al $^{3}$ (1998) & Trigone of right lateral ventricle & present & $\mathrm{n} / \mathrm{a}$ & $\mathrm{n} / \mathrm{a}$ \\
\hline 6 & Iwatsuki $^{7}$ (1999) & Trigone of left lateral ventricle & $\mathrm{n} / \mathrm{a}$ & Meningioma & $\mathrm{n} / \mathrm{a}$ \\
\hline 7 & Present case (2003) & Trigone of left lateral ventricle & present & Meningioma & $\begin{array}{c}\text { Posterior contralateral } \\
\text { transcollosal }\end{array}$ \\
\hline
\end{tabular}




\section{Table 2: General radiological features of metastatic renal cell carcinoma and meningiomas of the brain}

\section{Radiological feature}

CT

Plain CT density

Homogeneous CT contrast enhancement

Brain edema/vasogenic edema

\section{Calcification}

Broad based dural relationship

\section{MRI}

T1 intensity

Proton density and $\mathrm{T} 2$ intensity and edema

T1 with gadolinum-DTPA

Angiography

Angiography (tumor stain)

\section{Meningioma}

$75 \%$ hyperdense, $25 \%$ isodense

Present

Present

Usually minimal

$15-20 \%$

Present

$60-65 \%$ isointense, $30-35 \%$ hypointense

$50 \%$ isointense, $40 \%$ hyperintense,

$10 \%$ hypointense, + edema

Homogeneous enhancement with dural tail
Metastatic renal cell carcinoma

Hyperdense
Present
Present
Usually extensive
Absent
Absent

Isointense

Isointense, hyperintense + edema

Homogeneous enhancement

Tumor stain present

Figure 4: Histopathology of the renal cell carcinoma metastatic to the choroid plexus of the trigone. (A) Hematoxylin and eosin stain demonstrates a clear cell carcinoma with acinar growth pattern; delicate vascularized septa divide the cells into acinar structures. (B) A reticulin stain highlights the acinar architecture of this neoplasm. (C) This slide demonstrates that the tumor cells stain strongly for keratin. The cells also stained positive for epithelial membrane antigen (not shown).

of clear cells. A reticulin stain highlighted the nested nature of the tumor cells. The tumor cells stained positive for keratin and epithelial membrane antigen confirming the epithelial nature of the tumor. Stains for chromogranin and transthyretin were negative which ruled out a paraganglioma and choroid plexus adenoma, respectively. The normal choroid plexus cells stain was strongly positive for transthyretin. The nesting of the tumor cells and their bland nuclei caused the alternative interpretation of meningioma on frozen section.

\section{Discussion}

Seventeen cases of solitary metastasis from systemic cancers to the choroid plexus have been reported. These include lung, ${ }^{1,8-10}$ breast carcinoma and cutaneous melanoma, ${ }^{11}$ gastric carcinoma, ${ }^{12}$ bladder carcinoma, ${ }^{13}$ colon adenocarcinoma, ${ }^{1,14}$ neuroblastoma, ${ }^{15}$ lymphoma $^{16}$ and renal cell carcinoma. ${ }^{1,3-7}$ Among the 17 cases, nine tumors were located in the trigone of the lateral ventricles., ${ }^{1,3,-9,11,14-16}$ Table 1 summarizes the six previously reported cases of renal cell carcinoma metastatic to the choroid plexus, adding ours to the series.

In adult patients, intraventricular tumors in the region of the atrium are most commonly meningiomas. The incidence of meningiomas in the lateral ventricle has been reported in various series to be $1-2 \%{ }^{17,18}$ with the trigone being the most common location. The pre-operative radiological differential diagnosis of 
metastases to the choroid plexus also includes meningiomas and distinguishing between the two is difficult. Meningioma was the initial diagnosis in our case, as it was in at least one other case. ${ }^{7}$ A comparison of the radiological appearance of meningiomas and metastatic renal cell carcinoma is presented ${ }^{19}$ in Table 2. Of note the edema within the temporal and parietal lobes of our case was extensive and even when the temporal horn is trapped by an atrial meningioma causing obstructive hydrocephalus, it is usually not as pronounced.

Other tumors involving the choroid plexus are less common, and usually include metastases originating from gastric or lung cancer in adults, CNS lymphoma, and primary choroid plexus tumors in children. ${ }^{20}$ For metastases, the $\mathrm{CT}$ and MR findings are nonspecific and are usually contrast enhancing. Central nervous system lymphomas are increasingly prevalent and are seen at all ages, especially with the rise of immunocompromised patients. ${ }^{21}$ On nonenhanced CT, they show iso- to moderate hyperdensity. They are iso- to slightly hypointense on T1-weighted images, and are iso- to slightly hyperintense on T2-weighted images. Most lymphomas demonstrate strong, homogenous enhancement following contrast medium administration. Primary choroid plexus tumors are uncommon and consist of choroid plexus papilloma and choroid plexus carcinoma. Essentially, both primary tumors of the choroid plexus are very rare in adults, especially for the trigonal region. In young children typically under the age of five years, however, choroid plexus papillomas are the most common trigonal mass. ${ }^{22}$

The traditional neurosurgical approaches to lesions in the atrium of the lateral ventricle include the transcorticaltransventricular approach through the superior or middle temporal gyri or the superior parietal lobule and the ipsilateral transcallosal approach. The transcortical approaches in the dominant hemisphere has several limitations. They traverse normal brain, resulting in neurological deficits such as speech language disturbances, visual field deficits and parietal sensory dysfunction. ${ }^{23}$ Other limitations include there being fewer anatomic landmarks present, as compared to the transcallosal approach, to guide the surgeon to the ventricle, limited exposure and a tendency to produce postoperative seizures. ${ }^{24}$ The transcallosal approach has the advantage of avoiding a transcortical incision by going through the interhemispheric fissure and corpus callosum, provides identifiable anatomical landmarks, and does not require large ventricles. ${ }^{24}$ Furthermore, it has been demonstrated that this approach produces no postoperative seizures and tolerable neurological deficits. ${ }^{25}$ Lawton et $\mathrm{al}^{26}$ have described the contralateral transcallosal transventricular approach which improves upon the ipsilateral transcallosal approach in that it offers a better angle to increase the lateral exposure of the lesion and minimizes the retraction required on the medial side of the hemisphere opposite of the lesion. In addition, gravity helps pull the upside lesion medially into the surgeon's view. Furthermore, the contralateral transcallosal approach is ideal for left-sided lesions, as was the case with our patient, as the approach from the right protects the dominant hemisphere from potential retraction injury and sacrificing of bridging veins. Most importantly, however, many studies have demonstrated that the transcallosal approach is well-tolerated and produces no functional neurological deficits or postoperative seizures. ${ }^{26-29}$ The technique we have used in the present case is slightly different to that described originally by Lawton et $\mathrm{al}^{26}$ since we have made our incision and craniotomy as well as corpus collosotomy more posteriorly without experiencing any further complications.

One concern with a mid-posterior transcallosal approach is the presence and position of important parasagittal draining veins in the peri-central region. A pre-operative assessment of the veins can be made with an MR venogram and three dimensional reconstruction. If the surgeon encounters veins along the intended trajectory, only a small corridor is needed and dissection of the arachnoid along the course of the veins from the cortex to the superior sagittal sinus can frequently free up enough space so that the dissection can proceed. If a number of veins are encountered, we will sacrifice the smallest and most anterior of mutiple veins to assist the interhemispheric exposure. If it does not appear that any avenue can be safely obtained then the procedure should be abandoned. This has never been necessary in our experience.

Radiosurgery is an option for renal cell carcinoma metastatic to the brain. Gamma knife radiosurgery for renal cell carcinoma metastatic to the brain has been demonstrated to be effective. ${ }^{30}$ Using a dose of 18 Gray or greater, Shiau et $\mathrm{al}^{30}$ reported a local control of renal cell metastases in $90 \%$ of patients with one-year follow-up. However, this was not an option in our patient given the location of the tumor in the trigone of the left lateral ventricle, the sensitivity of the subependymal region to radiation, and the symptoms that she was developing secondary to obstructive hydrocephalus.

Renal cell carcinoma metastatic to the choroid plexus can mimic intraventricular meningioma. The differential diagnosis of an intraventricular tumor in patients even with a remote known history of renal cell carcinoma and a negative workup for a primary source of tumor should include both benign primary intraventricular tumors and metastases to the choroid plexus. The contralateral transcallosal approach is a surgical approach we recommend to such lesions of the left trigone.

\section{ACKNOWLEDGEMENTS}

We thank Dr. David Priest, neuroradiologist, for his assistance in reviewing the radiographic images.

\section{REFERENCES}

1. Kohno M, Matsutani M, Sasaki T, et al. Solitary metastasis to the choroid plexus of the lateral ventricle. Report of three cases and a review of the literature. J Neurooncol 1996;27:47-52.

2. Schreiber D, Bernstein K, Schneider J. [Metastases of the central nervous system: a prospective study. 3rd Communication: metastases in the pituitary gland, pineal gland, and choroid plexus (author's transl)]. Zentralbl Allg Pathol 1982;126:64-73.

3. Raila FA, Bottoms WT Jr, Fratkin JD. Solitary choroid plexus metastasis from a renal cell carcinoma. South Med J 1998;91:1159-1162.

4. Shigemori M, Shimamoto H, Noguchi S, et al. Choroid plexus metastasis of renal-cell-carcinoma. CT Kenkyu (Japan) 1987;9:603-606.

5. Mizuno M, Asakura K, Nakajima S, et al. [Renal cell carcinoma metastasizing to choroid plexus of lateral ventricle; a case report]. No Shinkei Geka 1992;20:469-474.

6. Matsumura H, Yoshimine T, Yamamoto S, et al. Single solitary metastasis of the slowly progressive type of renal cell carcinoma to the choroid plexus - case report. Neurol Med Chir (Tokyo) 1997;37:916-919. 
7. Iwatsuki K, Sato M, Taguchi J, et al. [Choroid plexus metastasis of renal cell carcinoma causing intraventricular hemorrhage: a case report]. No Shinkei Geka 1999;27:359-363.

8. Tanimoto $\mathrm{M}$, Tatsumi S, Tominaga $\mathrm{S}$, et al. Choroid plexus metastasis of lung carcinoma - case report. Neurol Med Chir (Tokyo) 1991;31:152-155.

9. Kart BH, Reddy SC, Rao GR, et al. Choroid plexus metastasis: CT appearance. J Comput Assist Tomogr 1986;10:537-540.

10. Healy JF, Rosenkrantz H. Intraventricular metastases demonstrated by cranial computed tomography. Radiology 1980;136:124.

11. Kendall B, Reider-Grosswasser I, Valentine A. Diagnosis of masses presenting within the ventricles on computed tomography. Neuroradiology 1983;25:11-22.

12. Nakabayashi H, Murata K, Sakaguchi M, et al. Choroid plexus metastasis from gastric cancer - case report. Neurol Med Chir (Tokyo) 1994;34:183-186.

13. Qasho R, Tommaso V, Rocchi G, et al. Choroid plexus metastasis from carcinoma of the bladder: case report and review of the literature. J Neurooncol 1999;45:237-240.

14. Al-Anazi A, Shannon P, Guha A. Solitary metastasis to the choroid plexus. Case illustration. J Neurosurg 2000;92:506.

15. Mertens R, Muhler E, Heimann G. [Disseminated neuroblastoma with intracerebral metastasis in a newborn infant]. Klin Padiatr 1987; 199:424-428.

16. Fukui K, Okamura K, Watanabe $\mathrm{M}$, et al. [Choroid plexus involvement in malignant lymphoma. Case report]. Neurol Med Chir (Tokyo) 1990;30:869-873.

17. Criscuolo GR, Symon L. Intraventricular meningioma. A review of 10 cases of the National Hospital, Queen Square (1974-1985) with reference to the literature. Acta Neurochir (Wien) 1986;83:83-91.

18. Rohringer M, Sutherland GR, Louw DF, et al. Incidence and clinicopathological features of meningioma. J Neurosurg 1989;71:665-672.

19. Ginsberg LE. Radiology of meningiomas. J Neurooncol
1996;29:229-238.

20. Guermazi A, De Kerviler E, Zagdanski AM, et al. Diagnostic imaging of choroid plexus disease. Clin Radiol 2000;55:503-516.

21. Roman-Goldstein SM, Goldman DL, Howieson J, et al. MR of primary CNS lymphoma in immunologically normal patients. AJNR Am J Neuroradiol 1992;13:1207-1213.

22. Knierim DS. Choroid plexus tumors in infants. Pediatr Neurosurg 1990;16:276-280.

23. Rhoton AL Jr, Yamamoto I, Peace DA. Microsurgery of the third ventricle: Part 2. Operative approaches. Neurosurgery 1981;8:357-373

24. Petrucci RJ, Buchheit WA, Woodruff GC, et al. Transcallosal parafornicial approach for third ventricle tumors: neuropsychological consequences. Neurosurgery 1987;20:457464.

25. Winkler PA, Ilmberger J, Krishnan KG, et al. Transcallosal interforniceal-transforaminal approach for removing lesions occupying the third ventricular space: clinical and neuropsychological results. Neurosurgery 2000;46:879-888; discussion 888-890.

26. Lawton MT, Golfinos JG, Spetzler RF. The contralateral transcallosal approach: experience with 32 patients. Neurosurgery 1996;39:729-734; discussion 734-735.

27. Geffen G, Walsh A, Simpson D, et al. Comparison of the effects of transcortical and transcallosal removal of intraventricular tumours. Brain 1980;103:773-788.

28. Jeeves MA, Simpson DA, Geffen G. Functional consequences of the transcallosal removal of intraventricular tumours. J Neurol Neurosurg Psychiatry 1979;42:134-142.

29. Oepen G, Schulz-Weiling R, Zimmermann P, et al. Neuropsychological assessment of the transcallosal approach. Eur Arch Psychiatry Neurol Sci 1988;237:365-375.

30. Shiau CY, Sneed PK, Shu HK, et al. Radiosurgery for brain metastases: relationship of dose and pattern of enhancement to local control. Int J Radiat Oncol Biol Phys 1997;37:375-383. 